Revista de Antropología Social

ISSN: 1131-558X

http://dx.doi.org/10.5209/RASO.61853

\title{
El don de la vida. Un análisis de la economía moral de la donación de gametos en Uruguay ${ }^{1}$
}

\author{
Mariana Viera Cherro ${ }^{2}$
}

Recibido: 30 de diciembre de 2017/Aceptado: 07 de junio de 2018

Resumen. En este artículo se analizan las prácticas y discursos que configuran la economía moral de la donación de gametos -óvulos y esperma- para intervenciones biotecnológicas con objetivos reproductivos en Uruguay. Con economía moral nos referimos a los valores y relaciones sociales implicados en las prácticas económicas. Analizamos dos asuntos especialmente disputados en el marco de esta economía moral: la adecuación o inadecuación de los procedimientos de acceso a ovocitos de donación y las maneras legítimas de retribuir la donación de gametos. La donación de gametos puede considerarse un tipo de bioeconomía en la que se genera y pone en circulación bienes sexualmente específicos: un gameto femenino u óvulo y un gameto masculino o esperma. El análisis de la economía moral de la donación de gametos busca problematizar los valores atribuidos a las biologías sexuadas en el contexto de esta bioeconomía y cómo estos valores inciden en las prácticas y discursos de la donación. Concluyo sobre la laxitud moral que acompaña la economía de la donación en Uruguay, en lo que tiene que ver con las personas donantes de ovocitos, a pesar de los riesgos clínicos concretos que tiene el proceso sobre estas.

Palabras clave: Moral; bioeconomía; donación; gametos; género.

\section{[en] The gift of life. Exploring the moral limits in the production and exchange of gametes for assisted human reproduction}

\begin{abstract}
In this article, we analyze the practices and discourses that shape the moral economy of the donation of gametes -oocytes and sperm- for biotechnological interventions with reproductive objectives in Uruguay. The proposal is to analyze the values and social relationships involved in economic practices. We analyze two issues that are particularly disputed in the framework of this moral economy: the adequacy or inadequacy of the procedures for accessing oocytes, and the appropriate retribution for the gametes. The donation of games can be considered a type of bioeconomy in which sexually specific goods are generated and put into circulation: a female gamete and a male gamete. The analysis of the moral economy of the donation of gametes seeks to problematize the values attributed to sexed biologies in the context of this bioeconomy, and how these values affect the practices and discourses of donation. I conclude about the moral laxity that seems to encourage the donation economy with oocyte donation, despite the clinic risks involved in the process.
\end{abstract}

Keywords: Moral; bioeconomy; donation; gametes; gender.

1 Este artículo está elaborado a partir de datos empíricos construidos en el marco de mi investigación doctoral en Antropología (Facultad de Humanidades y Ciencias de la Educación, Universidad de la República de Uruguay), investigación aún en curso. Agradezco a la Agencia Nacional de Investigación e Innovación (ANII) la beca otorgada para realizar el doctorado (marzo de 2015 a setiembre de 2017) y a la Comisión Académica de Postgrados de la Universidad de la República (Uruguay) por darme la beca de Finalización del Doctorado (marzo de 2018 a marzo de 2019).

$2 \quad$ Universidad de la República, Uruguay. marianaviera@yahoo.com 
Sumario. 1. Introducción. 2. Producción e intercambio de gametos: identificando los nudos del debate moral. 3. La donación de gametos como problema etnográfico multisituado. 4. Captación de donantes y disputas sobre el significado del altruismo. 5. Ovocitos y estrategias de maximización del valor. 6. A modo de cierre. 7. Referencias bibliográficas.

Cómo citar:Viera Cherro, M. (2018). El don de la vida. Un análisis de la economía moral de la donación de gametos en Uruguay, en Revista de Antropología Social 27(1), 287-306.

\section{Introducción}

La donación de gametos, en tanto práctica económica, supone un trabajo clínico (Waldby y Cooper, 2008) destinado a producir los gametos y una puesta en circulación de los mismos en instancias de adjudicación y uso. Tiene la particularidad de ser una forma literalmente corporal de trabajo reproductivo (Franklin, 1997; Waldby y Cooper, 2008) en el marco de una nueva forma de economía «(...) basada en la manipulación, explotación y apropiación tecnológica de la materia viviente» (Pavone, 2012:145) a la que algunos han denominado bioeconomía (Waldby y Cooper, 2008; Pavone, 2012).

Analizo dos asuntos especialmente disputados en el marco de esta economía moral de la donación de gametos: la adecuación o inadecuación de los procedimientos de acceso a ovocitos de donación y las maneras legítimas de retribuir la donación de material reproductivo. Me interesa analizar desde qué ámbitos se erigen estas disputas morales y, como contracara, cuáles son los posibles cuestionamientos a los procedimientos de obtención y asignación de material de donación reproductiva que quedan fuera de estas disputas.

A diferencia de otras bioeconomías, como la donación de órganos, la donación de gametos trabaja con bienes sexualmente específicos (un gameto femenino u óvulo y un gameto masculino o esperma). Esto ha llevado a la donación de gametos -y a las Técnicas de Reproducción Humana Asistida de forma más extensa-, a convertirse en una instancia privilegiada para analizar las relaciones entre economía, biología, género y biotecnologías.

En los primeros apartados presento la perspectiva epistemológica y metodológica desde la cual elaboro el análisis. Repaso en primer lugar antecedentes teóricos y empíricos de cómo se ha abordado la donación de gametos. En el siguiente apartado describo la metodología empleada para construir el material empírico y las dificultades para llevar adelante una investigación de este tipo en el contexto uruguayo. En los apartados siguientes analizo las prácticas y discursos que constituyen la economía moral de la donación de ovocitos en relación a los dos asuntos antes mencionados: las formas de acceso a los ovocitos y las formas de compensación por la donación de gametos.

El análisis aquí expuesto evidencia, como plantean Raymond (1995) y luego Stolcke (2010), que uno de los aspectos silenciados en la economía moral de la donación de gametos es el bienestar y los derechos de las mujeres que donan ovocitos, a pesar de los riesgos clínicos concretos que implica el proceso (Ariza, 2016a).

\section{Producción e intercambio de gametos: identificando los nudos del debate moral}

La producción y distribución de material reproductivo es un proceso que trabaja, material y simbólicamente, con biologías sexualmente específicas. No solo por esta 
especificidad biológica, sino por cómo se concibe y maneja en la práctica clínica dicha especificidad ${ }^{3}$, la donación de semen y la donación de óvulos no son procesos comparables en lo que se refiere a la obtención de uno y otro material reproductivo.

Mientras que para la donación de semen se requiere de un período corto (aproximadamente tres días) de abstinencia sexual al que le sigue la instancia de masturbación para obtener el semen, la producción de ovocitos comienza con el suministro de fármacos para llevar a los ovarios a una menopausia farmacológicamente producida, para luego estimularlos con la finalidad de que produzcan varios folículos ováricos ${ }^{4}$ más que los que producirían en un ciclo «normal». Mientras en un ciclo normal se producen uno o dos folículos ováricos, en un ciclo con intervención farmacológica se producen alrededor de veinte folículos. Luego estos folículos se aspiran, en un procedimiento que habitualmente se realiza con anestesia general. La persona que dona óvulos, además de tener que consumir las hormonas que estimulan la producción de ovocitos, debe ser controlada mediante ecografías transvaginales seriadas para saber cuándo es el mejor momento para realizar la punción.

La medicación para estimular la actividad de los ovarios puede tener consecuencias futuras sobre la salud de la donante, consecuencias que aún no se han investigado en profundidad. El proceso en sí mismo puede conllevar cambios de humor, sensación de pesadez, dolores de cabeza, malestar general e hinchazón y molestias a nivel del abdomen. El crecimiento de los ovarios a consecuencia de la medicación puede producir la torsión del ovario y en la punción del ovario se corre el riesgo de lesionar el intestino.

En países como Alemania, Austria y Suiza la donación de óvulos está prohibida, mientras que en Dinamarca y Suecia es considerada un procedimiento peligroso para la salud de las donantes. Debido a esto, en Suecia solo se permite emplear gametos sobrantes de mujeres que se sometan a reproducción in vitro por necesidades propias (Cambrón Infante, 2006). Esta prohibición da cuenta del valor otorgado a la salud de la mujer frente a la posibilidad de obtener ovocitos. En España la donación está permitida y es anónima, mientras en Gran Bretaña, si bien es un procedimiento habilitado, no tiene un carácter anónimo por lo cual se permite a quienes nacen a través de estos métodos conocer la identidad de los donantes. Esto ha provocado una disminución drástica de donaciones (Cambrón Infante, 2006).

La regulación jurídica de la donación de gametos da cuenta de algunos de los parámetros que conforman la economía moral de la donación, en cuanto al valor que la sociedad otorga a la salud de las personas donantes, las formas de relación social que pueden instituirse a través del intercambio del material reproductivo y el significado que tienen estos materiales biológicos. Al mismo tiempo, esta economía moral habilita algunas formas de intercambio y uso del material reproductivo.

En Estados Unidos, por ejemplo, al ser clasificados los gametos como tejidos que se regeneran, quedan fuera del ámbito de regulación de la donación de órganos, pudiendo ser comprados y vendidos (Waldby, 2008). Esto genera un mercado de óvulos altamente estratificado e internacionalizado (Waldby, 2008). En España y Corea, por su parte, el mercado de óvulos está vinculado al turismo médico y en Rumania lo que existe es un mercado de exportación de ovocitos (Waldby, 2008).

\footnotetext{
Para la donación de ovocitos, por ejemplo, se podría prescindir de la instancia de hiperestimulación farmacológica si alcanzara para los procedimientos con la producción de un solo folículo.

4 Los folículos ováricos se encuentran en el interior del ovario y envuelven los ovocitos. Durante la ovulación se activan y crecen hasta desarrollar un solo ovocito viable.
} 
Estos tres tipos de mercados mantienen e interseccionan inequidades de género, raciales y étnicas (Nahman, 2011).

Hay que advertir, además, que dependiendo del marco social, los ovocitos no solo ingresan en estos mercados como material para intervenciones con objetivos reproductivos, sino que los ovocitos in vitro tienen un potencial reproductivo que se bifurca entre su posible uso para estas intervenciones biotecnológicas, pero también para su uso en la producción de líneas de células madre embrionarias. Estas células madre son el material indispensable para la investigación en un terreno biotecnológico en creciente desarrollo: las terapias regenerativas (Waldby, 2008). La apertura de escenarios biotecnológicos que demandan este tipo de material reproductivo, aunado a la existencia de contextos sociales favorables a la producción y puesta en circulación de estos gametos, es un aliciente en el desarrollo de mercados.

Así, mientras la posibilidad de conocer la identidad de la persona donante sería un elemento que desestimularía la donación de ovocitos según lo que señala Cambrón Infante (2006) para el caso de Gran Bretaña, su comercialización podría llevar a aumentar la disposición a la donación, minimizando los riesgos físicos y psicológicos derivados del proceso que implica la necesaria estimulación ovárica y la extracción de óvulos (Directiva 23/2004/EC sobre Donación de Órganos y Tejidos, en Cambrón Infante, 2006). Por lo menos en España, la inclusión de la figura de la «compensación económica» para la donación de ovocitos en el año 1995, produjo un incremento exponencial de la cantidad de donantes.

A diferencia de la donación de ovocitos, la donación de semen no necesita de la intervención clínica. Que personas individuales puedan acceder a las muestras de semen sin intermediación de la clínica, nos enfrenta a la pregunta de si estamos ante un proceso biomédico que se articula a través de las «donaciones» o si estamos directamente frente a una industria (Spar, 2016; Álvarez y Pichardo, 2017), en la cual el semen es una mercancía que se vende, se compra y se distribuye (Álvarez y Pichardo, 2017). La exportación de semen desde Estados Unidos a otros lugares del mundo es un ejemplo de esta práctica y de la mercantilización de este bien. Marlene Tamanini (2015) rastrea la exportación de esperma desde Estados Unidos a sesenta países, teniendo como destinos principales Australia y Canadá, pero también Filipinas, Vietnam y México.

El otro cuestionamiento realizado a la puesta en circulación y uso de esperma de donación se vincula a su incorporación para proyectos parentales no heterosexuales o para la maternidad de mujeres sin pareja. En la práctica, sin embargo, este tipo de parejas o personas son las que más demandan gametos de donación. En torno a un $60 \%$ de los demandantes de gametos en Estados Unidos son actualmente mujeres solteras o parejas homosexuales (Tamanini, 2015). Esto es similar a lo que sucede en Uruguay, donde de cada cinco muestras de esperma, cuatro están destinadas a parejas de mujeres o mujeres sin pareja (Entrevista con especialista, 12/3/2015).

\section{La donación de gametos como problema etnográfico multisituado}

Este artículo toma cuerpo en el marco de una investigación más amplia de corte etnográfico que actualmente realizo para culminar mi tesis doctoral en Antropología Social. La etnografía es el modo de producción teórica que caracteriza al quehacer antropológico. Supone una aproximación de primera mano a los temas de investigación 
y al contexto en el cual estos cobran sentido. Se vale de métodos y técnicas como la observación participante, la entrevista en profundidad y el análisis de producciones textuales (marcos normativos, textos de prensa...), entre otros. La generalización en la etnografía resulta de la ampliación de la capacidad interpretativa del material empírico producido en contexto para otras realidades, no del análisis de una porción del universo social concebida como muestra representativa de la totalidad de ese universo.

El encuadre epistemológico-metodológico de esta investigación se orienta hacia lo que Marcus (2001) definió como una etnografía multilocal, en tanto la delimitación del campo escapa a los límites de la etnografía tradicional, restringida al espacio de la comunidad. La etnografía multilocal se desarrolla en un tiempo-espacio difuso en el que el campo, en tanto porción de lo real que se desea conocer (Guber, 2004), resulta de un trazado que vincula procesos, escenarios y personas en una elaboración compleja del problema de investigación. Este trazado da cuenta de una posición teórica, pero que dialoga con el proceso empírico, por lo cual no está definido a priori, sino que se va realizando en el curso mismo de la investigación (Marcus, 2001).

Para abordar la donación de gametos para TRHA en el marco de la investigación doctoral de la que surge este artículo se ha entendido necesario recorrer diversos escenarios: los debates en el Parlamento al discutirse el proyecto de Ley de regulación de las técnicas de reproducción humana asistida (Ley 19.167); opiniones sobre la Ley y las TRHA en los medios de comunicación masiva y espacios clínicos en los cuales se procede a la obtención y asignación de material reproductivo de donación. Además de analizar estos escenarios, y para captar la complejidad del fenómeno, se propuso «seguir a las personas» (Marcus, 2001), entrevistando a personal técnico involucrado en estos procesos, donantes y receptores.

Antes de describir las actividades realizadas en el marco de esta etnografía, importa señalar que en Uruguay existen solamente dos clínicas que poseen Programas de Donación de Óvulos -el Centro de Reproducción Humana (CERHIN) y la Clínica Suizo Americana-, y un solo laboratorio (de aquí en adelante El Laboratorio) que tiene un Programa de Donación de Semen y un Programa de Donación de Óvulos, que abastece de óvulos al Centro de Esterilidad de Montevideo (CEM) que nuclea varias clínicas que no cuentan con Programas de Donación de Óvulos ${ }^{5}$, y de semen al CEM, al CERHIN y a la Clínica Suizo Americana. Estas son las tres clínicas autorizadas por el Ministerio de Salud Pública (MSP) para realizar los procedimientos de alta complejidad ${ }^{6}$ en el marco del sistema de copago dispuesto por la Ley 19.167. Las tres trabajan en Montevideo y el CERHIN tiene además una dependencia que funciona en el Norte del país.

Lo que el Estado aporta como co-pago por los tratamientos está en función de los ingresos de la mujer o pareja solicitante y disminuye según la cantidad de intentos insatisfactorios que la pareja realice, de acuerdo al detalle que se expresa en la siguiente tabla?:

5 Dentro del CEM hay dos clínicas que realizan la captación y la hormonación de las donantes de forma independiente, pero recurren a El Laboratorio para los exámenes clínicos, así como a la infraestructura del Programa de Ovodonación de El Laboratorio para la aspiración de los ovocitos, la fecundación in vitro y la transferencia del embrión o los embriones.

6 En medicina reproductiva se distingue entre procedimientos de baja complejidad y alta complejidad. La baja complejidad es la inseminación, que supone la introducción de semen (propio o de donación) en la vagina de la mujer por medio de un catéter. La alta complejidad refiere a las intervenciones en las que la fecundación se produce de forma extracorpórea, in vitro, para luego transferirse el embrión a la persona que lo gestará.

7 Fuente: Fondo Nacional de Recursos. http://www.fnr.gub.uy/sites/default/files/tnoticia/doc/copagos_2018.pdf Valores vigentes hasta el 31-12-2018 


\begin{tabular}{|l|c|c|c|}
\hline Tramo de ingreso de la pareja & Primer Intento & Segundo Intento & Tercer Intento \\
\hline $\begin{array}{l}\text { Primer tramo (hasta } 38.480 \text { pesos) } \\
\text { aproximadamente } 1.200 \text { dólares }\end{array}$ & $\begin{array}{c}\text { 0\% (lo cubre el } \\
\text { Fondo de Recursos } \\
\text { en su totalidad) }\end{array}$ & $10 \%$ & $20 \%$ \\
\hline $\begin{array}{l}\text { Segundo tramo (de } 38.481 \text { a } 76.960 \text { pesos) } \\
1.200 \text { a } 2.400 \text { dólares }\end{array}$ & $\begin{array}{c}25 \% \text { (la pareja } \\
\text { debe pagar la cuar- } \\
\text { ta parte del costo } \\
\text { del tratamiento) }\end{array}$ & $50 \%$ & $65 \%$ \\
\hline $\begin{array}{l}\text { Tercer tramo (76.961 a } 130.832 \text { pesos) } \\
2.400 \text { a } 4.000 \text { dólares }\end{array}$ & $50 \%$ & $70 \%$ & $85 \%$ \\
\hline $\begin{array}{l}\text { Cuarto tramo (130.833 a } 230.880 \text { pesos) } \\
4.000 \text { a } 7.215 \text { dólares }\end{array}$ & $75 \%$ & $85 \%$ & $90 \%$ \\
\hline $\begin{array}{l}\text { Quinto tramo (más de } 230.881 \text { pesos) } \\
\text { Más de } 7.215 \text { dólares }\end{array}$ & $85 \%$ & $90 \%$ \\
\hline
\end{tabular}

Es importante señalar que El Laboratorio no atiende pacientes, no es una clínica de reproducción humana asistida. Solo ve a personas o parejas que están atravesando un proceso de reproducción asistida en el caso que necesiten material reproductivo de donación para evaluar el material que debe asignárseles; o parejas que necesitan un «tratamiento» del semen del varón, con el fin de congelar una muestra propia y utilizarla en un futuro, o para «mejorar» una muestra que va a utilizarse en una intervención de alta o baja complejidad por quien la aportó. El Laboratorio gestiona, por tanto, dos Bancos de Semen: un Banco A, de semen propio, y un Banco B, de semen de donación.

Las actividades realizadas como parte del proceso etnográfico fueron variadas, desplegándose diversas técnicas según los contextos.

Realicé observación participante en El Laboratorio, desde marzo de 2015 a noviembre de 2016. Allí asistí a diferentes momentos en los que se gestiona la obtención y asignación de material reproductivo de donación. Pude observar las dinámicas de atención desde la sala de espera y, especialmente, cómo se organizan las entrevistas con donantes y parejas receptoras para resguardar el anonimato. Participé de las primeras entrevistas que se les realizan a quienes se candidatean para la donación de gametos, del trabajo clínico de evaluación del esperma y de la preparación del esperma, tanto propio como de donación, previo a dárselos a quienes van a realizarse un procedimiento in vitro o una inseminación de baja complejidad.

Para acceder a las entrevistas con quienes se candidatean a la donación acordamos con las especialistas que estaban encargadas de realizar estas entrevistas - una uróloga en el caso de quienes se candidatean a la donación de semen y una laboratorista para la donación de óvulos ${ }^{8}$-, que yo esperaría fuera del consultorio hasta que

8 Esta primera entrevista es diferente según se esté realizando para el Programa de Donación de Semen o de Óvulos. En ambos casos se explica a quienes se presentan a los Programas los requisitos para la donación y qué implica el procedimiento en términos de filiación. La diferencia es que, para quienes se presentan para donar esperma, en esta primera entrevista se les realiza una serie de preguntas relativas a antecedentes médicos familiares y propios y se les explica en qué consiste el procedimiento de donación de esperma, mientras que estos últimos dos asuntos para el caso de la donación de ovocitos, se conversan en la siguiente entrevista que se realiza con el ginecólogo. 
ellas preguntaran a las personas si me daban permiso para entrar. En todos los casos accedieron a mi participación, que se limitó a observar la entrevista entre la especialista y quien se estaba candidateando a la donación de material reproductivo. No utilicé ninguna forma de registro dentro de la consulta, sino que tomaba notas una vez fuera, no solo de la consulta, sino de El Laboratorio.

Además del trabajo de campo en El Laboratorio, realicé trabajo de campo en dos Laboratorios In Vitro: uno que funciona en coordinación con los Programas de Donación de Gametos de El Laboratorio y otro donde realiza los procedimientos in vitro una de las clínicas privadas que tiene su propio Programa de Donación de Ovocitos. En ambos lugares pude observar el procedimiento de aspiración y recuperación ${ }^{9}$ de ovocitos, mejoramiento de las muestras de esperma, inseminación e $\mathrm{ICSI}^{10}$, congelamiento y descongelamiento de embriones, selección de embriones y transferencia de los mismos. También observé y participé de la dinámica general que implica el trabajo en el laboratorio in vitro, que además de los procedimientos técnicos supone comunicación y gestión de pacientes-donantes y trabajo administrativo.

El acceso al campo, pero sobre todo la continuidad del trabajo en estos diversos escenarios, fue compleja. Entiendo que ello se debe en gran medida a que las TRHA son miradas con recelo en Uruguay y eso hace que quienes trabajan en este campo estén generalmente a la defensiva de lo que pueda decirse. Esta sensación de estar haciendo algo con lo que la sociedad más amplia, o los vínculos sociales más cercanos, no están completamente de acuerdo, fue un comentario que de forma constante me hizo el personal técnico. A este recelo, se suma la dificultad de acceder a donantes y receptores de material reproductivo por el anonimato que por ley debe regir la donación y por el ocultamiento que impera sobre esta práctica, particularmente, entre quienes reciben material reproductivo de donación y quieren pasar por una familia «normal», lo que Bergmann (2012) define como el passing for.

Para ingresar a El Laboratorio solicité un permiso que fue firmado por el director de la institución, con quien me entrevisté en tres ocasiones, la primera para solicitar este aval. De todas maneras, y más allá de contar con una aceptación expresa para realizar trabajo de campo en ese espacio institucional, la posibilidad misma de desarrollar las tareas de investigación dependió, en gran parte, de la mayor o menor disposición del personal técnico, con el que estaba en contacto directo. La mejor disposición de la médica que está directamente encargada de la evaluación de los donantes de semen y de la adjudicación de este material reproductivo, me permitió desarrollar mayor cantidad de actividades vinculadas a la donación de semen que a la donación de ovocitos. En el caso del semen, pude acceder al registro de todos los donantes desde que El Laboratorio comenzó a desarrollar esta actividad en 1988, hasta la actualidad, y pude participar también de un mayor número de entrevistas a quienes se candidateaban para la donación. En el caso de las donantes de ovocitos, la especialista no me permitió acceder al registro de donantes que El Laboratorio llevaba, invocando el argumento de que «la donación es anónima».

9 Se denomina recuperación a la separación de los ovocitos del líquido folicular y de las células del cúmulo en el que llegan al laboratorio luego de la punción. Luego de separados se limpian y se guardan en una máquina que los mantiene a $37^{\circ} \mathrm{C}$.

10 Intracytoplasmic Sperm Injection o Inyección Intracitoplasmática de Espermatozoides. Es una técnica por la cual se fecundan los ovocitos inyectando un espermatozoide en su citoplasma. A diferencia de la fecundación in vitro clásica, que necesita de 50 o 100 mil espermatozoides, para la ICSI alcanza solo con uno. 
El anonimato supone que quienes reciben material reproductivo no conocen la identidad de quien provee ese material, y viceversa. Mi interés no era develar tales conexiones, que además no están contenidas directamente en el registro de donantes -según pude constatar cuando accedí al de donantes de semen -. Apelar al anonimato por parte de la especialista fue, básicamente, una manera de restringirme el acceso a esa información. La relación con esta especialista estuvo todo el tiempo permeada de sospechas sobre qué hacía yo en ese espacio, más allá de las explicaciones que le di en las reiteradas ocasiones que me lo preguntó.

La ruptura definitiva con El Laboratorio se produjo luego de que acompañara a una candidata a donación de ovocitos a la entrevista con la psicóloga, prevista en el periplo de la donación. La candidata, a quien yo había conocido en El Laboratorio durante la primera entrevista que allí le realizaron, me invitó a acompañarla en todo el proceso de la donación, proceso que no pudimos culminar porque ella quedó embarazada. Previo a esta noticia, fuimos juntas a la consulta con la psicóloga. Allí me presenté como la antropóloga que estaba investigando sobre donación de gametos. Pensé que iba a ser muy fácil que la psicóloga me habilitara a participar de la entrevista, sobre todo porque yo la había entrevistado previamente, ella había sido sumamente amigable y abierta al diálogo, e incluso me había sugerido escribir un artículo juntas, cosa que por supuesto nunca hicimos. En esta oportunidad en cambio, y luego de hacernos esperar un largo rato, hizo pasar a la candidata a donar ovocitos y le dijo que no iba a entrevistarla porque en ese momento ya no tenía tiempo, que iba a derivarla a otra colega y que no podía presentarse conmigo a la consulta sin informar de ello previamente. Después de este suceso telefoneé varias veces a la técnica encargada de seguir el proceso de la Donación de Semen, pero siempre me dijo que no había donantes agendados. Lo mismo hice con la embrióloga encargada del trabajo en el Laboratorio in Vitro, para saber si existía la posibilidad de realizar nuevamente observación participante en ese ámbito, pero en todas las oportunidades me respondió que en ese momento estaban con demasiado trabajo, que debía llamar unos meses después. Casi en simultáneo, me llegaban constantes notificaciones por mensajes de correo electrónico de que había personas leyendo artículos que he escrito sobre TRHA y que circulan en Internet. En esos trabajos se refleja mi perspectiva crítica en relación a estas biotecnologías.

Realicé entrevistas en profundidad a:

- 6 técnicos/as de El Laboratorio: su director (urólogo), dos técnicas (una uróloga y una laboratorista) y un técnico (ginecólogo) que trabajan directamente en los Programas de Donación de Gametos, una psicóloga que realiza la evaluación psicológica de quienes ingresan en estos programas (tanto donantes como receptores) y la embrióloga encargada del Laboratorio in Vitro A.

- 1 técnica (ginecóloga): directora de una de las clínicas, que además de El Laboratorio, tiene Programa de Donación de Óvulos y que realiza sus procedimientos en el Laboratorio in Vitro B.

- 1 técnico (ginecólogo), director de una clínica que tiene Programa de Donación de Ôvulos.

- 1 técnica (abogada) que trabaja en la institución, Instituto Nacional de Donación y Transplante de Células, Tejidos y Órganos ${ }^{11}$.

11 Este organismo integra, junto con representantes del Ministerio de Salud Pública (MSP), de las Facultades de Medicina, de las Facultades de Derecho, de la Sociedad Uruguay de Reproducción Humana, del Colegio Médico del 
Además de estas entrevistas en profundidad tuve conversaciones informales con diferentes especialistas durante el trabajo de campo en los diversos ámbitos (El Laboratorio y los dos Laboratorios in Vitro). El contacto y posterior entrevista con donantes y receptores de gametos fue posible, en la totalidad de los casos excepto tres, gracias al personal técnico.

Entrevisté a tres candidatos a donación de semen. Dos de ellos eran estudiantes universitarios y el tercero no estudiaba, trabajaba y practicaba un deporte a nivel de competencia. También entrevisté a cuatro candidatas a donación de óvulos del Programa de Donación de Óvulos de El Laboratorio. Una de ellas estudiante universitaria, otra estudiante de una especialización técnica y las otras dos trabajadoras. A los candidatos los conocí a través de las entrevistas que les realizó la técnica y que yo pude presenciar. Lo mismo con dos de las personas que se candidateaban para donar ovocitos. En todos los casos una vez culminada la entrevista técnica les solicitaba un número para luego llamarles y preguntarles si aceptaban una entrevista en profundidad. En ningún caso la realicé en el ámbito clínico porque me interesaba darles un margen de tiempo para decidir si realmente querían aceptar la entrevista y no asociar esa instancia a su periplo por la donación. Me interesaba remarcar que, si bien había accedido a sus contactos gracias al personal técnico, lo que dijeran en la entrevista no iba a condicionar su aceptación como donantes. Por esta razón decidí descartar una entrevista que, más allá de lo anterior, tuve que realizar en el espacio del consultorio ${ }^{12}$. A las restantes dos candidatas a donación de ovocitos las contacté porque una de las candidatas que ya había entrevistado las conocía y me pasó sus teléfonos. Luego entrevisté a un donante de semen, también estudiante universitario, cuyo contacto me lo pasó una de las técnicas de El Laboratorio.

En el Laboratorio in Vitro B pude contactar para entrevistar a una donante de ovocitos en paralelo ${ }^{13}$, que donaba parte de sus ovocitos en el marco de un tratamiento in vitro propio y que estaba con su pareja varón; una receptora de semen, que también estaba con su pareja varón; y una donante de ovocitos pura o simple. En el transcurso de la entrevista a la mujer receptora de semen y su pareja varón me enteré que ella también había sido donante de ovocitos hacía siete años en el contexto de un tratamiento in vitro previo del que había nacido la única hija de la pareja. En aquella ocasión también habían tenido que recurrir a semen de donación.

En los casos de las parejas en tratamiento reproductivo, busqué agendar la entrevista antes de que se confirmara o no el embarazo, por el impacto que la noticia, fuera positiva o negativa, podía tener en su disposición a entrevistarse conmigo. Luego supe que ninguna de las dos intervenciones fue exitosa.

Uruguay y de los usuarios, la Comisión Honoraria de Reproducción Humana Asistida creada por la Ley 19.167. Esta Comisión tiene entre sus cometidos asesorar al MSP en relación a las políticas de reproducción humana asistida, promover las normas para la implementación de la reproducción asistida y considerar para su aprobación protocolos de investigación relacionados con las técnicas de reproducción asistida.

12 Una vez que la técnica terminó de realizar la primera entrevista a esta candidata a donación de ovocitos me dijo que podía hacerle la entrevista ahí y en ese momento. Lo dijo delante de la candidata y, a pesar de mi negativa, me lo planteó como algo sobre lo cual no tenía opción. No sé si lo hizo con ánimo de colaborar con mi investigación y conmigo, o de señalarme que era ella quien podía tomar ese tipo de decisiones. Yo ya le había dicho que las entrevistas las iba a hacer después, fuera de la institución. Pero en ese momento negarme a su sugerencia significaba romper con su autoridad y pensé que eso traería peores consecuencias que hacer la entrevista, aunque sintiera durante todo el intercambio que estaba vulnerando a la candidata y a mí misma.

13 Se llama donación de ovocitos en paralelo a aquella que realiza una mujer que está pasando por un tratamiento in vitro para tener descendencia. De los ovocitos que se recuperan, una parte se asigna a la mujer-pacientedonante y otra parte se asigna a una mujer-receptora. En lo que se denomina donación pura o simple, en cambio, la donante no está en tratamiento reproductivo, sino que pasa por el proceso de hormonación y recuperación de ovocitos con el objetivo de donar todos los que puedan recuperarse. 
La donante simple trabaja para una empresa de limpieza. Según me dijo en la entrevista, si bien su interés por la donación no estaba en la retribución económica, lo que le daban como compensación equivalía a cuatro meses de alquiler (Ent. Rocío, 21-3-2018). Ella vive con su pareja y tres hijos. La mujer en tratamiento que donaba lo hacía a cambio de costear parte de su intervención in vitro, necesaria porque su pareja no tenía buenas condiciones espermáticas. Iban a intentar con semen de donación, pero «al final se nos presentó esta oportunidad», me explicó Luana en la entrevista (Ent. Luana y Marcel, 9-3-2018). La otra pareja, que había sido donante en la intervención de hacía siete años, habían realizado este intento porque su hija quería un hermanito. Tuvieron que solicitar un préstamo a un banco privado para pagar la in vitro, porque no tenían otros recursos económicos y consideraban que el trámite para hacerlo vía el co-pago que habilita la legislación vigente les resultaba muy engorroso (Ent. Rocío y Marcos, 13-3-2018)

También entrevisté a una receptora de ovocitos a quien contacté gracias a una amiga común. Ella esperaba ovocitos del Programa de Donación de Óvulos de El Laboratorio.

Las entrevistas al personal técnico fueron realizadas en su totalidad en los lugares de trabajo de los/as entrevistados/as. Las entrevistas a donantes y receptores/as fueron realizadas en los lugares en los que los y las entrevistadas me sugirieron. La mayoría en mi lugar de trabajo, una en mi casa, otra en el trabajo de una de las candidatas a donación de ovocitos, mientras que la donante de ovocitos que contacté en el Laboratorio in Vitro B me pidió realizar la entrevista en su trabajo, que es un lugar abierto al público. La entrevista a la pareja receptora de semen la realicé en su casa, en una localidad suburbana en el interior del país. La entrevista a la pareja en la que ella había donado ovocitos en el ciclo que yo había presenciado, la hice en el cuarto de hotel en el que habían hecho el reposo luego de la transferencia del embrión y antes de volver a su localidad en la que residían, en el interior del país. La entrevista a la receptora de óvulos que contacté gracias a una amiga que ambas tenemos en común, la realicé en mi lugar de trabajo. Su pareja no pudo estar presente porque vive en el interior del país en un lugar de muy difícil acceso. Ella también vive allí, pero viaja habitualmente a la capital para realizarse los exámenes e intervenciones. En el momento en que la entrevisté estaba esperando que le adjudicaran donante.

Todas las entrevistas fueron grabadas con permiso de quienes entrevisté, excepto en un caso en el que el especialista no lo quiso, y posteriormente transcriptas por mí. Todas las personas que participaron de la investigación fueron debidamente informadas sobre el objeto de la investigación y sobre la institución en el marco de la cual se estaba llevando a cabo. También se les garantizó la confidencialidad de los datos obtenidos y el resguardo del anonimato, por lo que todos los nombres que utilizo son ficticios. Es cierto que en el caso de las instituciones el anonimato resulta difícil en un contexto de tan pocas clínicas.

\section{Captación de donantes y disputas sobre el significado del altruismo}

En Uruguay existen dos maneras de acceder a ovocitos de donación: donación pura y donación mixta o en paralelo. Proceden a obtener ovocitos por donación pura el Programa de Donación de Óvulos de El Laboratorio y algunas clínicas que trabajan nucleadas en el CEM y, por tanto, en forma muy directa con El Laboratorio en los pro- 
cesos de evaluación médica de quienes se candidatean a donar y en la instancia de fecundación in vitro, y otra de las clínicas que trabaja con donación simple y también con donación en paralelo. La donación pura se recompensa mediante lo que se denomina lucro cesante ${ }^{14}$. La donación en paralelo, por su parte, supone que la paciente-donante reciba de la receptora de sus óvulos el aporte económico para su intervención.

En la otra clínica que realiza donación de ovocitos en paralelo, según me aclaró su responsable, no estaban pudiendo obtener ovocitos de donación porque la nueva ley no permite la donación mixta en tanto no permite que las donantes sean mujeres que estén en tratamientos reproductivos (DdeC ${ }^{15}$, especialista, 30-11-2016). En la ley 19.167 no existe ningún impedimento expreso con respecto a este tipo de donación, y de hecho esta se sigue realizando. Lo que dice el Decreto que reglamenta esta Ley (Decreto 84/015) es que quienes donan, tanto ovocitos como esperma, deben ser personas jóvenes y sanas, pero qué constituye una persona sana está abierto a la interpretación.

Para quienes proceden a la obtención de los ovocitos por donación de óvulos pura, la donación en paralelo que practican otras clínicas no puede considerarse altruista. No la consideran altruista porque entienden que preguntarle a una paciente si quiere convertirse en donante mientras está atravesando una intervención con objetivos reproductivos implica cierto grado de coerción (Ent., especialista, 30-3-2015).

La idea de coerción que me explica uno de los técnicos entrevistados que trabaja en los Programas de Donación de Gametos de El Laboratorio, no implica condicionar el acceso a los tratamientos reproductivos a la donación, sino que es mucho más sutil, y remite a la relación de inequidad que existe entre médico y paciente.

Porque existe una asimetría entre el paciente y el médico que la gente dice 'me pidió el médico. Yo no quiero hacerlo, pero si le digo que no, se va a enojar, no me va a atender'. (Ent. especialista, 30-3-2015)

En un artículo anterior (Viera, 2016) analizaba cómo las diferentes prácticas -donación pura, donación en paralelo- asumen diversas concepciones de qué significa una donación altruista y cómo esta disparidad genera, asimismo, distancias morales entre quienes practican uno u otro procedimiento para el acceso al material biológico. Para quienes practican la donación pura los que realizan donación en paralelo son amorales porque coaccionan a las mujeres. Una de las técnicas de El Laboratorio me dijo, en una conversación informal, que ella era de la idea de no dar semen de donación a estas clínicas justamente porque no estaba de acuerdo en cómo se manejaban con la donación de ovocitos (DdeC, especialista, 25-5-2016).

Para quienes practican la donación en paralelo, a su vez, lo que resulta amoral es pagar por los gametos de donación -con pago se estaría refiriendo al dinero recibido por quienes donan como lucro cesante-, mientras el modo de proceder por donación mixta sí sería altruista en tanto no se compensa de forma económica a la donante (DdeC, especialista, 30-11-2016).

14 Por lucro cesante se entiende una suma de dinero que quien dona recibe por el tiempo y las molestias invertidas en el acto de la donación. La donación de óvulos se compensa con 16.000 pesos uruguayos (aproximadamente 500 dólares) que se van abonando en la medida en que la mujer va completando las diversas instancias de estimulación hormonal, recuperación de ovocitos y control posterior a la donación. En el caso de la donación de semen, ésta se compensa con 38 dólares americanos por muestra aportada.

15 Abreviatura para Diario de Campo. Son las notas tomadas durante el proceso etnográfico. 
En términos de trabajo clínico (Waldby y Cooper, 2008), este sistema de obtención de ovocitos, mediante el procedimiento denominado mixto o en paralelo, tiene menos costos biológicos para quien realiza la donación, porque se trata de donantes que, en tanto también son pacientes, ya están transitando por procesos de hiperestimulación hormonal para la sobreproducción de ovocitos como parte de sus intervenciones para materializar su deseo de descendencia biológica (Diniz y Gómez Costa, 2006). Sabemos que uno de los mayores problemas de la estimulación hormonal orientada a la producción de mayor cantidad de ovocitos que los que el cuerpo genera sin intervención hormonal -de uno a dos por ciclo ovulatorio-, es su impacto sobre la salud a largo plazo de quienes pasan por este tipo de intervenciones con consecuencias todavía insuficientemente estudiadas. Esto ha llevado a Dickenson (en Waldby, 2008) a señalar que la donación de óvulos debe equipararse más a la donación de riñones que a la donación de esperma, que supone un procedimiento en absoluto invasivo para la salud de quien dona.

En la Ley 19.167 no se establece un tope máximo de donaciones de ovocitos, aunque existe un consenso de que no resulta recomendable que una misma persona done más de cinco veces. Si bien las clínicas están obligadas a registrar todos los procedimientos con donación, sea que una parte la pague el Estado o los costos sean asumidos por la mujer o por la pareja en su totalidad -me explicaba una de las especialistas que trabaja en los procesos de control de estos procedimientos (DdeC. especialista, 11-5-2017)-, no existe seguridad de que los procedimientos que se realizan de forma privada estén debidamente informados. Pero además las tres clínicas que funcionan no tienen, hasta el momento, un sistema unificado de registro de donantes, esto hace que una misma donante de óvulos puede estar registrada con diferente número en cada una de las clínicas y, eventualmente, donar hasta cinco veces en cada una de ellas.

Tampoco están suficientemente estudiadas las posibles repercusiones psíquicas que tiene para las donantes-pacientes el hecho de dar parte de sus ovocitos en un contexto social en el que los buenos óvulos parecen ser el material definitorio del éxito o no de las intervenciones con fines reproductivos ${ }^{16}$, y en el marco de un proceso que resulta generalmente angustioso para las personas y parejas. Como advierten Roberts y Throsby (2007), quienes transitan por la reproducción asistida pasan por múltiples intervenciones y experimentan una angustia significativa derivada de su incapacidad para concebir. Este esquema que Roberts y Throsby (2007) han señalado para Inglaterra como una situación en la que todos ganan -win-win situation-, exacerba esta vulnerabilidad. Pero para quienes trabajan en la captación y gestión de gametos de donación en Uruguay, si bien el impacto del procedimiento en la persona-donante no resulta un asunto a desconsiderar, las pugnas morales no se sitúan en qué tipo de procedimiento genera más o menos impacto en términos de salud, sino en qué modo de proceder se ajusta más al sentido dado al altruismo, o más bien los sentidos diversos dados a un concepto que la ley asume como unívoco. La ley 19.167 en su artículo 12 del Cap. III dice únicamente que la donación debe ser altruista. Ni

16 En base a esta convicción, en Uruguay se generó un acalorado debate sobre si era o no pertinente extender el copago por parte del Estado para tratamientos en mujeres que, aun teniendo más de 40 años, recurrieran a ovocitos de donante, porque entonces sus posibilidades de éxito reproductivo dependían de la edad de la donante. (Programa Desayunos Informales de Canal 12. Disponible en: https:/www.youtube.com/watch?v=vbsJQrpmvAU. Acceso: 10/2/2017 
la ley ni el decreto reglamentario ( $\left.\mathrm{N}^{\circ} 84 / 015\right)$, promulgado en febrero de 2015 , definen qué debe entenderse con ese concepto.

Lo que sí existe, desde cualquiera de estas perspectivas, es un esfuerzo por separar conceptualmente el intercambio de gametos de los intercambios mercantiles. La utilización del concepto de lucro cesante, así como otros similares -honorarios, viáticos, gratificación, compensación, indemnización o retribución-, es parte de un agenciamiento sociotécnico a través del cual se previene la ocurrencia de un pago en tanto precio, buscando así producir una diferencia entre un intercambio de mercado y uno que no lo es (Ariza, 2016b). Por eso el lucro cesante no se concibe como un pago por la donación, sino como una retribución por las molestias causadas. Cuando algunos técnicos que practican la donación mixta advierten que el lucro cesante es asimilable a un pago por la donación (DdeC, especialista, 30-11-2016) lo que se está poniendo en cuestión es el carácter no mercantil del procedimiento. De la mano del debate moral en torno al modo de captación de donantes, está el debate sobre el carácter mercantil o no de la donación.

Quienes defienden la donación simple y altruista no descartan que pueda haber otro tipo de intereses -fundamentalmente económicos-, más allá del altruismo. «Porque es un poco utópico pensar que no les importe el dinero, ¿verdad?», señalaba uno de estos especialistas (Ent., especialista, 12-3-2015). Como ilustra Marcel Mauss en su «Ensayo sobre el don» (2009), que un intercambio no tenga un carácter mercantil no significa que las partes carezcan de interés económico o no establezcan cálculos económicos en relación a dichas transacciones.

Lo que desde la perspectiva de quienes practican la donación simple se argumenta es que ninguna donación se sostiene solo en el interés económico, sino que debe haber otros intereses en juego para quien dona.

[...] lo primero que los moviliza es que quieren conseguir plata. Pero el que quiere conseguir plata rápido y fácil, $[\ldots]$ cuando le mandás el primer interrogatorio ya se dan cuenta que no es para ellos. Porque es un proceso muy largo, que tienen que cumplir con muchas cosas [...] y también hay formas mucho más fáciles de conseguir dinero, y más dinero. (Ent., especialista, 12-3-2015)

En el caso de la donación de ovocitos, a diferencia de la de esperma, a la que se refería la especialista antes citada, parece necesario, por lo que esta donación implica, un componente importante de «disposición a ayudar al prójimo», según interpreta otra técnica que trabaja directamente con quienes donan ovocitos.

[...] me parece como que el elemento solidaridad por lo menos es lo que pienso que tiene que haber. Porque no es fácil la donación. Además, eso te tiene que salir, no es solo la donación, implica compromiso con las consultas, compromiso con los estudios, todo eso previo, después que te aceptan como donante, ir a los controles, hacerse más estudios de sangre, las ecografías, ir a la parte de la aspiración. Entonces si la disposición no es ayudar al prójimo se complicaría, me parece que ellas lo sienten. (Ent., especialista, 17-3-2015) 
Otra de las técnicas también se refiere a la necesidad de que exista solidaridad para la donación, pero reconoce que hay otras formas de compensar la donación que resultan en una motivación para la misma «[...] a veces es una manera un poco indirecta de saber que la fertilidad está bien, de recibir un poco la compensación de que están ayudando a otros... [...]» (Ent., especialista, 2-7-2015)

Este tipo de rango de retribuciones, también se busca poner en consideración a la hora de captar posibles donantes. Así a frases como «Donar semen es ayudar» y «Tu donación vale», que circulan a través de la publicidad gráfica destinada a esta instancia de captación, se suman otras como «¿Sabías que donar semen/óvulos tiene beneficios para vos?».

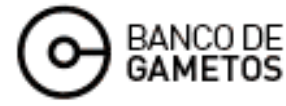

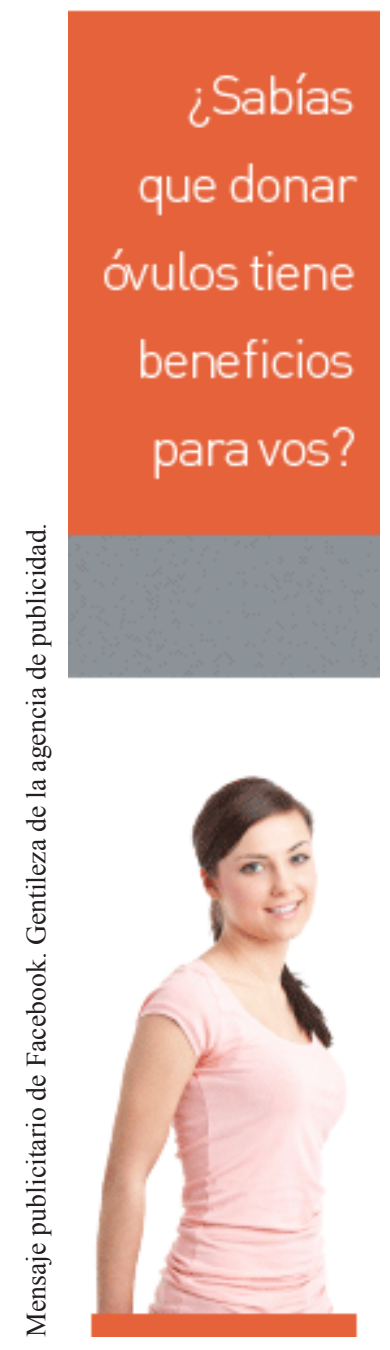

Así, mientras el especialista que trabaja en una de las clínicas que practica donación en paralelo entiende que la donación pura no es altruista, en tanto se compensa económicamente, quienes realizan este último tipo de procedimiento no otorgan un carácter mercantil a la donación, porque sostienen que el dinero que se da es únicamente una compensación, es decir, no hay una equivalencia monetaria entre todo lo que implica el acto de la donación y el monto de dinero que se da a cambio, y porque la motivación económica por sí sola no alcanzaría para sostener la donación. Pero más allá de negar el carácter mercantil de la donación, para quienes practican la donación pura lo que hace posible el altruismo en la donación de gametos es el modo en que se capta a quienes donan; una donación altruista es aquella en la que no existe coerción para la donación.

Tanto desde esta perspectiva como desde la del especialista que criticaba el hecho de que se compensara la donación con un monto de dinero por concepto de lucro cesante, señalando que eso hacía de la donación de gametos un intercambio mercantil, el altruismo resulta del modo de proceder del sistema de gestión de la donación de material reproductivo. Vemos así que el carácter altruista de la donación tiene sentidos disímiles que repercuten en el modo de proceder a la captación de ovocitos.

La responsable de la otra clínica privada, que practica la donación en paralelo hace 19 años, no problematizó las formas de acceso a las donantes o la retribución dada a la donación en relación al altruismo. El énfasis de la técnica estuvo puesto en que, al trabajar con personas que tienen un objetivo gestacional, la paciente-donante se compromete en el proceso, lo que a veces no ocurre con la donante pura.

La paciente que solo viene a donar, bueno, el objetivo seguramente es el tema económico, porque se le da un viático, que eso nos autorizaron a hacerlo. No es una paciente consciente [la donante pura], como la otra [la donante mixta], porque no todas, pero muchas no siguen a rajatabla el tratamiento, hay que andarlas persiguiendo. Es otro objetivo que tienen (Ent., especialista, 11-9-2017). 
Resulta interesante la definición que la especialista hace de la donación mixta, que no se fundamenta en el modo de acceso a la donante, que es en lo que ponen el énfasis quienes practican la donación pura, ni en la retribución económica que puede obtenerse por la donación. La especialista distingue una y otra forma de proceder de acuerdo a como se distribuye el material biológico recuperado: «[...] donante pura es la que dona todos los óvulos que se obtienen en ese ciclo, y donante mixta es la que usa la mitad de los óvulos y la otra mitad los dona» (Ent., especialista, 11-9-2017).

Según entiendo, esta reformulación que realiza la especialista tramita la dificultad de obtener ovocitos de donación -lo que implica conseguir donantes que se mantengan partícipes durante todo el proceso-, en términos moralmente aceptables. En un contexto de pocas posibilidades de acceso a ovocitos de donación ${ }^{17}$, se desarrollan estrategias materiales para conseguir donantes de la mano de una moral que sustente tales estrategias.

Otra de las estrategias que sigue esta clínica es pedir a las mujeres que están pasando por un proceso de reproducción asistida

[...] que traigan una donante, de esa forma ella sube en la lista que nosotros tenemos. Esa receptora no va a ser para ella, la confidencialidad es clave. [...] La otra es a través de las redes (Ent., especialista, 11-9-2017).

Igual que para quienes practican la donación en paralelo, la compensación económica por lucro cesante no parece ser suficiente para conseguir mujeres dispuestas al trabajo clínico (Waldby y Cooper, 2008) que requiere la donación de ovocitos, asumiendo las posibles consecuencias de este proceso sobre la salud a largo plazo, además de la incomodidad que muchas veces acarrea durante el mismo proceso (inflamación del abdomen, cambios en el humor...). Conseguir donantes de ovocitos en Uruguay es difícil (DdeC. especialista, 11-5-2017).

Los ovocitos son así los huevos ${ }^{18}$ de oro de la reproducción asistida (Stolcke, s/d), porque su obtención requiere de un trabajo clínico (Waldby y Cooper, 2008) de alto costo, que en algunos países como Argentina, España o Estados Unidos, directamente se traduce en el lenguaje mercantil, pagándose a las mujeres altas sumas de dinero a cambio de su material biológico, mientras en otros como Uruguay, donde la mercantilización de la donación de ovocitos resulta amoral, quienes gestionan el acceso a este material reproductivo elaboran estrategias diversas que les permitan acceder y aprovechar al máximo un recurso biológico tan valioso, al tiempo que actuar de acuerdo a la moralidad vigente, que como vimos es una moralidad en disputa.

Debemos recordar que los ovocitos no son solo valiosos por la dificultad de contar con personas dispuestas a darlos ni por lo que implica el trabajo clínico para su recuperación. Son también valiosos porque se considera que gran parte del éxito de los tratamientos reproductivos dependen de la calidad de los ovocitos, como señalábamos antes.

17 Este fue uno de los mayores impedimentos para la realización del trabajo de campo, ya que había pocas personas que se candidateaban para la donación de ovocitos, muchas de ellas agendaban entrevista y luego no se presentaban o abandonaban el proceso cuando se informaban acerca de lo que suponía la donación en términos de tiempo e involucramiento físico.

18 Stolcke juega con el doble significado que en inglés, lengua en la que está escrito el artículo, tiene la palabra egg, que significa huevo pero también ovocito. 
En lo que sigue analizo cómo se construye el valor de este material reproductivo y abordo las estrategias que siguen las clínicas y Programas de Donación de Ovocitos para aprovechar al máximo este recurso biológico que se entiende de tanta valía. Me interesa mostrar que no se trata solamente de obtener ovocitos, sino de maximizar su uso, poniendo en tensión el cuidado de la donante y el aprovechamiento de lo que puede aportar su biología reproductiva.

\section{Ovocitos y estrategias de maximización del valor}

Como señalaba la especialista en cuya clínica se practica la donación en paralelo, el compromiso de la paciente-donante con el proceso que insume la donación de ovocitos en la donación en paralelo es algo dado, porque la paciente-donante realiza el proceso de estimulación hormonal y posterior recuperación de ovocitos para materializar su deseo gestacional. En la donación pura, en cambio, el compromiso de la donante con el proceso es una interrogante.

[...] nos ha sucedido de pacientes [donantes puras] que nos han abandonado en la mitad del tratamiento, que eso una paciente mixta no lo hace [...] Es un costo agregado, porque el fondo no previó que haya pacientes que estudiemos y que nos queden afuera, que eso significa un costo para la clínica. (Ent., especialista, 11-9-2017).

Por eso, uno de los aspectos en los que se hace más énfasis en el sistema de donación pura es en la «medición del compromiso de la donante». Por cierto, quienes practican este tipo de donación no lo expresan en estos términos y tampoco refieren lo que implica el abandono de una donante del proceso de donación en términos económicos. Como mencionábamos antes, se busca no evidenciar la dimensión económica que implica el procedimiento.

Como en la donación pura este compromiso de completar el proceso no es algo que se pueda garantizar a priori, resulta esencial para quienes trabajan en la gestión de la donación de ovocitos sopesar la confiabilidad de quien dona. El primer contacto con quienes se candidatean a la donación se realiza generalmente por vía del correo electrónico, tanto para donantes de esperma como para donantes de óvulos, y en ese primer contacto si se «[...] ve que no son confiables ya se les responde desestimulándolos a seguir» (DdC, 18/4/2015), explicaba una de las especialistas. La confianza es clave porque permite invertir en alguien que se asume va a continuar con el proceso. Esta confianza supone que quienes donan van a actuar de acuerdo con los requisitos que se les solicita para participar de los Programas de Donación.

El trabajo clínico (Waldby y Cooper, 2008) para la donación de semen supone un control de la sexualidad y los consumos, un disciplinamiento en aspectos de la vida cotidiana de quienes donan. Se pide a quien dona que tenga un cuidado general con su salud para no tener infecciones que incidan en la muestra; si se detectan infecciones una vez pasado el período ventana (tres meses) la muestra se descarta. También se le solicita que no consuma drogas o alcohol. En lo que afecta a la sexualidad, se piden 48 horas de abstinencia de actividad sexual coital. En el caso de la donación de óvulos, la obtención de un producto de valor (óvulos) supone también un disciplinamiento con relación a la toma de medicación y la realización de los 
controles requeridos. Durante ese período se aconseja no tener relaciones sexuales o utilizar preservativo para prevenir un embarazo. Además de que un embarazo coartaría la posibilidad de continuar con el proceso de donación, existe el peligro de la multigestación a consecuencia de la sobreproducción de óvulos inducida por la estimulación hormonal.

En cualquiera de los dos casos - donación de óvulos o donación de esperma-, se apela a un sujeto neoliberal, capaz de evaluar el riesgo y de tomar decisiones responsables (Brown, 2016). Esta ideología neoliberal, advierte Pavone (2012), resulta indispensable para sostener este tipo de economías: «Biotecnología e ideología neoliberal representan así las dos caras de una moneda, una moneda que se conoce como bioeconomía» (Pavone, 2012:154).

Resulta interesante, por otra parte, notar la diferencia en la producción de valor de uno y otro gameto (óvulo y esperma). En el caso del esperma, la calidad de la muestra resulta de la cantidad y calidad de los espermatozoides y ello depende únicamente del proceder de quien dona y de cualidades físicas que se evalúan como parte del proceso de aceptación del donante. En el caso de los óvulos, si bien la cantidad es importante, en tanto se trata de que quien dona tome medicación para producir más de un ovocito, lo más importante es que el embarazo se produzca. «No importa si se recupera un solo ovocito, si el resultado es satisfactorio alcanza» (Ent. especialista 17/3/2015). De todas formas, no hay manera de saber cómo va a responder la persona a la medicación, por lo menos no en la donación simple. Eso nos permite señalar que, en el caso de quienes donan óvulos, no es el material lo que resulta clave para poder ser o no donante; la fertilidad en el caso de los óvulos se produce mediante la intervención medicamentosa, mientras en el caso del semen, si bien la muestra puede mejorarse, su calidad está sujeta sobre todo a las características y conductas de quien dona.

Esto hace que, en principio, cualquier cuerpo femenino sea mercantilizable. Por otro lado, los requisitos de inversión y beneficios en el marco del proceso llevan a que se tienda siempre a una mayor estimulación, lo que Tamanini (2009) define como una fabricación del ovario reproductivo. Ella lo señala en cuanto foco de preocupación para las mujeres que pasan por tratamientos reproductivos, pero también es lo que sucede en el caso de la estimulación a donantes para la producción de ovocitos que puedan ingresar a los Programas de Donación. Según Laborie (en Tamanini, 2009), esta búsqueda de la superproducción de óvulos es, en cierto modo, tratarlos como a los espermatozoides, para llevarlos de una economía de la escasez a otra de la superabundancia: de uno por período a lo máximo que se pueda lograr. Sin embargo, llevarlos a la superabundancia no supone que haya un consumo que acompañe esta sobre productividad. Si bien una donante puede ser estimulada hasta recuperarse dieciséis ovocitos, puede resultar que de esa cantidad de gametos se utilicen solo dos. Ello depende de si el especialista que atiende a la mujer receptora «quiere o no compartir a la donante. Depende de cómo le gusta trabajar al especialista» (Ent. especialista, 17/3/2015).

Sea por la razón que sea, por cómo está acostumbrado o prefiere trabajar el especialista o sea porque la receptora no quiere compartir óvulos de la misma donación con otra paciente, lo que podemos afirmar es que la estimulación para la producción de ovocitos a utilizar depende, no de quien dona, sino del/a técnico/a o de quien recibe los óvulos. Considerando que se trata de un trabajo clínico que para el caso de la donación de ovocitos conlleva riesgos sanitarios aún no del todo analizados, quien dona se pone en el mismo 
riesgo sea que se utilicen uno o dieciséis óvulos. Podemos advertir que, si la donación debe ser altruista, el modo en que se practica habilita a que la recepción sea egoísta.

\section{A modo de cierre}

En este artículo he buscado dar cuenta de algunas de las características centrales de la economía de la donación de gametos para TRHA en Uruguay, subrayando dos debates, mutuamente imbricados, que delinean la economía moral (Kopytoff, 1991) de estos procesos. Estos debates se centran en cómo debería procederse para la captación de donantes de ovocitos - este es un debate que produce distancias éticas entre los especialistas en Uruguay-, y cómo debería compensarse la donación de gametos en general. En relación a esto último, se está unánimemente de acuerdo en que la donación de gametos no puede convertirse en una práctica mercantil.

En estos debates juegan un rol central las disputas en torno a cómo concebir el altruismo, principio que debe regir la donación según la normativa vigente. Este es un asunto especialmente sensible para el caso de la captación de donantes de ovocitos, por ser este un bien escaso, altamente valorado y difícil de conseguir, y para cuya obtención se requiere de un trabajo clínico (Waldby y Cooper, 2008) con consecuencias aún no suficientemente bien estudiadas sobre la salud de quien dona.

Pero, más allá de las disputas sobre qué supone que una donación sea altruista, existe un esfuerzo general por distinguir la donación de gametos del intercambio mercantil. No se trata de desconsiderar que puede haber otros intereses, incluso económicos, en la donación, y no solamente la intención de ayudar a otra persona. Sino de no evidenciar que existen lógicas neoliberales que acompañan y sostienen estos procedimientos bioeconómicos (Waldby y Cooper, 2008; Pavone, 2012).

Podemos señalar entonces que las disputas morales que constituyen la economía moral de la donación de gametos para TRHA en Uruguay, se centran en las disputas en torno a cómo concebir al altruismo de la donación y cómo en la práctica esas concepciones habilitan o inhabilitan diversos procedimientos de captación de donantes de ovocitos.

La preocupación sobre la cantidad de veces que alguien puede pasar por un proceso de estimulación hormonal para la donación de ovocitos no es central en el marco de esta economía moral. Si bien es una preocupación incluida en el Decreto Reglamentario (84/015) de la Ley 19.167, que en el Capítulo IV referido a la donación de gametos y embriones señala que la donación de óvulos se realizará «Hasta cinco (5) estimulaciones por donante, no más de tres (3) en un año y hasta veinticinco (25) nacimientos por donante», la investigación empírica muestra que aún no existe un control efectivo de este requisito legal.

Además de la dificultad en la administración de este requisito y de la falta de problematización sobre este aspecto de la economía moral de la donación, debemos mencionar que, a diferencia de lo que ocurre con la donación de semen cuya fertilidad se evalúa, la fertilidad de los ovocitos se produce a instancias de la administración de hormonas en la persona donante.

Todos estos elementos nos advierten sobre la laxitud moral que parece acompañar la economía de la donación en lo que tiene que ver con los cuerpos y personas productoras de ovocitos en el marco de esta empresa bioeconómica. 


\section{Referencias bibliográficas}

Álvarez Plaza, Consuelo; Pichardo Galán, Ignacio (2017). «Mercancía o don: Bancos de semen y autonomía reproductiva». AIBR Revista de Antropología Iberoamericana, 12 (3): 339-363.

Ariza, Lucía (2016a). «Cuerpos abstractos, riesgos concretos: dispositivos clínicos y la salud de las donantes de óvulos en la medicina reproductiva argentina». Salud Colectiva, 12(3): 361-382.

- (2016b). «'No pagarás': El Consentimiento Informado como productor de solidaridad en la medicina reproductiva». Ciencia, Docencia y Tecnología, 27, 52: 240-268.

Bergmann, Sven (2012). «Resemblance that matters: on transnational anonymized egg donation in two european IVF clinics»», en M. Knecht, M. Klotz, S. Beck (Eds.) Reproductive Technologies as Global Form. Ethnographies of Knowledge, Practices, and Transnational Encounters. Frankfurt: Campus Verlag, 331-355.

Brown, Josefina (2016). «El aborto en cuestión: la individuación y juridificación en tiempos de neoliberalismos». Sexualidad, Salud y Sociedad, 24, diciembre: 16-42.

Cambrón Infante, Ascensión (2006). Los óvulos en el mercado. UIMP: Galicia.

Diniz, Débora; Gómez Costa; Diniz, Rosely (2006). «Infertilidad e infecundidad: acceso a nuevas tecnologías reproductivas», en C. F. Cáceres, et al. (Orgs.). Sexualidad, estigma y derechos humanos: desafios para el acceso a la salud en América Latina. Lima: FASPA/UPCH, 55-67.

Franklin, Sarah (1997). Embodied Progress. A cultural account of assisted conception. Nueva York: Routledge.

Guber, Rosana (2004). El salvaje metropolitano. Buenos Aires: Paidós.

Kopytoff, Igor (1991). «La vida social de las cosas. La mercantilización como proceso», en A. Appadurai (ed.). La vida social de las cosas. Perspectiva cultural de las mercancías. México D. F: Grijalbo Editorial, 89-124

Marcus, George (2001). «Etnografía en/del sistema mundo. El surgimiento de la etnografía multilocal». Alteridades, 11(22): 111-127.

Mauss, Marcel (2009 [1925]). Ensayo sobre el don. Buenos Aires: Katz.

Nahman, Michal (2011). «Reverse traffic: intersecting inequalities in human egg donation». Reproductive BioMedicine Online, 23: 626-633.

Peirano, Mariza (2014). «Etnografia não é método». Horizontes Antropológicos, julio-diciembre, $\mathrm{N}^{\circ}$ 42: 377-391. Disponible: http://dx.doi.org/10.1590/S0104-71832014000200015

Raymond, Janice G. (1995). Women as Wombs. Reproductive Techonologies and the battle over women's freedom. Australia: Spinifex Press.

Stolcke, Verena (2010). «Homo clonicus, ¿entre la naturaleza y la cultura?». Campos, $11(2): 9-34$.

Stolcke, Verena (s/d). «El sexo de la biotecnología». Disponible en: https://periodicos.ufsc. br/index.php/ref/article/viewFile/12039/11316 (Acceso 24 de enero de 2015)

Tamanini, Marlene (2009). Reprodução assistida e gênero. O olhar das ciências humanas. Florianópolis: Editorial da UFSC.

- (2015). «Maternidades são Políticas: da Fecundidade, dos Especialistas, das Mulheres, dos laboratorios, das Tecnologias e Muito Mais», en M. Vosne y G. Arias (Orgs.). Políticas de Gênero na América Latina. San Pablo: Paco editorial, 171-196.

Viera Cherro, Mariana (2015). Tecnologías de Reproducción Asistida y deseo del hijo en el Rio de la Plata. Universidad de la República: Montevideo.

- (2016). «Moralidades y reproducción asistida en el Rio de la Plata», en C. Straw, E. Vargas, M. Viera Cherro, et al. (Orgs.). Reprodução assistida e relações de gênero na América Latina. Curitiba: Editorial CRV, 239-264. 
Waldby, Catherine (2008). «Oocyte markets: women's reproductive work in embryonic stem cell research». New Genetics and Society, Vol. 27, No. 1, March: 19-31

Waldby, Catherine; Cooper, Melinda (2008). «The biopolitics of reproduction. Post-Fordist Biotechnology and Women's Clinical Labour». Australian Feminist Studies, 23:55: 57-73 